\title{
Measuring competitive self-focus perspective taking, submissive compassion and compassion goals
}

\author{
Paul Gilbert ${ }^{1 *}$, Francisca Catarino ${ }^{2}$, Joana Sousa ${ }^{3}$, Laura Ceresatto ${ }^{4}$, Rosalind Moore ${ }^{1}$ and Jaskaran Basran ${ }^{1}$
}

\begin{abstract}
Background: Research in the last 20 years has provided good evidence that developing compassion-focused motives for self and others has a range of benefits. However, people can behave in prosocial ways for different reasons, not all of which are genuinely care focused. This paper reports research comparing submissive compassion (being helpful to be liked) to "genuine" compassion in relation to domains of empathy and perspective taking. We developed a new short (5 item) self-report scale (the competitive perspective taking scale) to explore how people might use perspective taking for self-focused reasons. We investigated its association with validated empathy and compassion measures.
\end{abstract}

Methods: One hundred ninety nine students completed a range of questionnaires including a new short (5 item) self-report scale 'The Competitive Perspective Taking Scale' online or on paper at the end of lectures or during lecture breaks.

Results: Compassionate goals were positively correlated with the empathy quotient and its subscales. However, submissive compassion had a small negative correlation with the social skills subscale on the empathy quotient and was unrelated to other subscales. In addition, submissive compassion, unlike compassionate goals, was associated with submissive behaviour, shame, self-criticism, depression, anxiety and stress. Competitive perspective taking was positively correlated with cognitive empathy on the emotional quotient but not emotional reactivity or social skills.

Conclusion: These findings indicate there are individual differences in compassion motivation and the competencies of compassion, such as empathy and that these should be measured separately. In addition, the findings suggests that the higher peoples cognitive perspective taking, the more they are able to recognise their ability to use empathy for beneficial reasons.

Keywords: Compassion, Depression, Empathy, Perspective talking, Self-criticism, Shame, Submissive compassion

\section{Background}

Compassion for self and others has become a major focus of scientific study in terms of its benefits on health and social relationships (e.g. $[17,42]$ ), physiology [45] and potential as a focus for psychotherapy [19-21, 28, 29]. However, people can behave in prosocial ways for different reasons, not all of which are genuinely care focused $[8,14]$. For example, some individuals engage in caring behaviour

\footnotetext{
* Correspondence: p.gilbert@derby.ac.uk

${ }^{1}$ College of Health and Social Care Research Centre, Centre for Compassion

Research and Training, University of Derby, Derby, UKDE22 1GB

Full list of author information is available at the end of the article
}

because they want to be seen positively, valued and accepted [8]. Others may engage in caring behaviour because they do not want to be shamed, or feel guilty for not caring [36]. Understanding peoples motives that can sit behind compassion and their competencies such as empathy are clearly important in health care and other helping professions.

Catarino et al. [9] developed a self-report measure to explore what they termed submissive compassion. These motives that can underpin caring behaviour, link with Goffman's [26] seminal work on 'presentation of self in everyday life' on how individuals can try to ingratiate 
themselves with others, particularly when they feel inferior, subordinate or in submissive positions [32, 40]. Catarino et al. [9]) found that in a sample of university students submissive compassion was significantly related to self-image goals $(r=.51)$, caring guilt and caring shame, submissive behaviour, depression, anxiety and stress, in a way that genuine compassion was not.

For people with social anxiety, ingratiating oneself by 'trying to be kind and helpful' can be a safety strategy for acceptance [44]. Furthermore, although a number of studies have shown that compassion is linked to the personality traits of agreeableness and conscientiousness, Bègue et al. [6] showed that these traits in a Milgram type study, where are an authority asks to deliver electric shocks to another, are also associated with conformity, obedience and not wanting to cause trouble by refusing to obey. Presumably the fear of offending the authority over-rides compassion motives to not shock the confederate. This raises the core issue about 'courage' as being central to compassion rather than just wanting to help people or be 'nice and agreeable' ([21]). Work by Crocker and Canevello [10,11] shows that compassion goals can be attenuated by self focussed ego goals such as avoiding being shamed and wanting to be recognised.

\section{Empathy and perspective taking}

All motivations, be they harm avoidance, food seeking, infant caring or sexuality require competencies to fulfil the goals of the motive. Without an ability to do something about a motive it would be ineffectively engaged. Empathy, as a competency, commonly linked with compassion, enables a depth of social understanding of the minds of self and others. It is a competency that can be used for many social motives [7, 22, 23]. Empathy has different elements particularly distinguishing it from sympathy (a feeling of distress linked to seeing suffering), emotional empathy (linked to emotional contagion, sharing, attunement or resonance), and perspective taking and mentalising (a cognitive, imaginative and effortful process) [12]. Although compassion and empathy are sometimes conflated with the concept of 'empathic concern', the different competencies of empathy have different evolutionary histories and function in different ways [39]. Panksepp and Panksepp [39] argue that the evolution of emotional contagion and resonance arose from how fear spreads between conspecifics. So that if one is in danger from a predator and distress calls, other can take flight. There are many examples where empathy need not inspire compassionate action or sentiments [7]. For example, imagine watching someone take revenge on a "a nasty bad guy in a movie". If we (empathically) emotionally resonate with that desire for vengeance and pleasure in seeing 'the bad person' suffer, that would clearly not be compassionate to the victim.

\section{Self-focused empathic perspective taking}

Bloom [7] and Zaki [46] show that empathy can be associated with different motives and that certain types of motive (e.g. defending against others seen as threatening, and self-interest) can turn off empathy (e.g. to outsiders). So it is motives that influence the use and focus of empathic competencies. We are more likely (to want) to empathise and mentalise with people we love than people we hate $[34,46]$. It is also possible to be compassionately orientated but have poor empathic competencies and impose care inappropriately [30]. In contrast, others may be competent perspective takers, but have little compassion motivation or interest, as might be the case for people with psychopathic difficulties [37]. Galinsky et al. [18]) distinguished between feeling for another person (empathising with) and thinking about the situation of another (perspective taking). In competitive situations or negotiations, perspective taking (which need not involve emotional connectedness) may be more helpful than emotional empathy, whereas in interpersonal caring situations, emotional connectedness is important. Perspective taking can help in a whole variety of social roles such as competing for a job or seeking sexual partners. What is of interest is whether people recognise they can use their empathic and perspective taking skills to manipulate others should they so wish $[25,33]$ also indicate that empathy and menatalising can be related to the social role that one is in. For example, some individuals find being empathic easier in caring in contrast to competitive relationships and vice versa. In other words, it is what is being empathised with that is crucial.

To date there is no measure that explores the degree to which people are aware that they can use their empathic competencies for self-interest and even to manipulate others. Nevertheless, it is possible that people can choose how they want to use their empathic skills and competencies. For example, people with psychopathic tendencies can show forms of empathic perspective taking when directed to do so [37]. In addition, Shirtcliff et al. [41] explored neurobiological pathways in individuals who display little empathy and suggested that these impairments are not necessarily due to a reduced ability to understand others but reduced sensitivity to distress; that is they are low on caring motivation [22, 23].

This study therefore sought to develop a measure of what we might call competitive self-focused or even manipulative empathy, whereby people are aware that they can use their empathic competencies non-compassionately to gain personal and competitive advantage; for example 
being able to understand other people in order to entice them to behave in one's own self-interest. We suspect that individuals who have empathic competencies will have enough empathic insight into their own motives to recognise that they can use empathy compassionately or for selfinterest.

Although it is well recognised that empathic skills are important for health workers researchers do not always control for the motivation behind empathy. Hence, the ability to study people's empathic competencies, that can be used for self-interest or defensively, is important in healthcare. Indeed, although not measured here, patients may well pick up that clinicians can be empathic, but still lack caring motivation.

\section{Study: aims and objectives}

The essence of this study is therefore to explore how certain forms of helping and compassionate behaviour are defensive (i.e. submissive compassion). Second to highlight that empathy is a competency not a motive and therefore can be used for different motives. In addition, that individuals can be aware how they use empathy for self-interest and can be assessed in self-report. This study had a number of aims.

1. To further develop research on 'submissive compassion' by exploring its relationship with empathy variables, shame and self-criticism. It is unclear if submissive compassion is related to empathy or if problems with empathy increase submissive compassion. We hypothesise that submissive compassion would have little relationship with empathy or a negative one.

2. Although empathy is often associated with prosocial motivation, increasing evidence is pointing to the fact it can be associated with more narcissistic and malevolent intention. To date, however, there is no measure to explore people's natural awareness of their ability to use empathy this way. Hence we developed a simple measure of 'competitive' selffocused perspective taking to tap people's awareness of their ability to use empathic and perspective taking for self-advantage. We hypothesised that individuals who rate themselves as empathic will also have insight into the fact that they can use empathy for self-focused reasons.

3. Given that many of these variables have been related to gender variation, we also explored gender differences across all variables. We hypothesise that females are likely to be higher on measures of empathy and compassion variables, but may be equally able to recognise that empathy can be used competitively.

\section{Method}

\section{Participants and procedure}

Students from a British University completed questionnaires (online) or on paper at the end of lectures or during lecture breaks. Participants were 88 male and 111 female students, between 18 and 57 years of age (mean $=26.64, \mathrm{SD}=8.08)$. All participants read an information pack, gave consent and filled out the study questionnaire pack. They were subsequently given a debriefing sheet and $£ 2$ for their participation.

\section{Measures}

\section{Submissive Compassion Scale [9]}

Submissive compassion is a 10-item scale that assesses the desire to appear likeable and reduce the fear of rejection by being helpful e.g., 'I worry that if I am not caring enough, people will reject me'. Participants rate a 5point Likert scale, from zero ("Not at all like me") to four ("Extremely like me"). The scale has good internal consistency. with a Cronbach's alpha of .89 [9].

\section{Submissive Behaviour Scale [1]}

The Submissive Behaviour Scale offers 16 examples of submissive behaviour (e.g. "I agree that I am wrong even though I know I'm not") rated as a behavioural frequency (from zero $=$ Never to four $=$ Always). The scale has good validity and reliability, with a Cronbach's alpha of .89 and 4-month test-retest reliability of $r=.84, p$ $<.001$ with a student population [1].

\section{Friendship Compassionate and Self-Image Goals Scale $[10,11]$}

This 13-item scale assesses compassionate and selfimage goals. All items began with the phrase "In the past week, in the area of friendships, how much did you want to or try to," and are rated one ("Not at all") to five ("Always"). A compassionate goal is: "have compassion for others' mistakes and weaknesses." A self-image goal is "avoid showing your weaknesses". Both subscales have high internal consistency with Cronbach alpha's of .83 for the self-image goals and of .90 of for the compassionate goals [10].

\section{The Other as Shamer Scale [27]}

The 18 item OAS measures external shame. Participants rate items on a 5-point scale according to the frequency they feel others judge them negatively (zero = Never to four $=$ Almost always). Items include 'I feel 
other people look down on me'. In the original study the scale showed a Cronbach's alpha of .92 .

\section{The Forms of Self-Criticising/Attacking and Self- Reassurance Scale [24]}

This scale explores how people think about themselves when they make mistakes or things go wrong for them. There are two self-critical factors. One is feeling inadequate and a failure. The second is self-hating. A third factor measures a reassuring way of thinking about oneself. The scale has a probe statement 'When things go wrong for me' and participants rate 22 statements on a five-point scale $($ zero $=$ Not at all like me to four $=E x$ tremely like me). Examples include 'I think I deserve my self-criticism' (inadequate self), and 'I find it easy to like myself' (reassured self). The Cronbach's alphas in the original study were above .86 for each subscale.

\section{Reading the Mind in the Eyes Test [5]}

This is a social-perceptual test of mental state reasoning that shows convergent validity with the selfreport Empathy Quotient also used in this study [3]. The test consists of 36 pictures of eyes, presented in a letterbox style expressing different emotions such as "panicked", "surprised", "cautious". Participants have a record sheet, the stimulus set and a list of word definitions and choose which word out of four different options best describes the emotional state of that person.

\section{The Empathy Quotient Scale [4, 31, 43]}

The Empathy Quotient, was used in the study. Previous factor-analytic studies have distinguished between three subscales named 'cognitive empathy', 'emotional reactivity' and 'social skills', based on 28 items rather than 40 or 60 items [31]. Studies suggest that these subscales provide a more refined evaluation of a person's empathic skill. Participants rate how strongly they agree (Strongly Agree to Strongly Disagree) with a series of statements relating to cognitive empathy (e.g. 55. "I can tell if someone is masking their true emotion"), emotional reactivity (e.g., 42. "I get upset if I see people suffering on news programmes") and social skills (e.g. 8. "I find it hard to know what to do in a social situation"). Cronbach's alphas were .84 for cognitive empathy, .76 for emotional reactivity, .57 for social skills and .85 for the combined 28 items [38].

\section{The Competitive Perspective Taking Scale}

This 5-item scale (see Table 1) was developed to measure competitive self-focused perspective taking.
Table 1 Factor loadings for the competitive empathy scale

\begin{tabular}{ll}
\hline Scale Items & Factor 1 \\
\hline 3. If I were an interrogator I would know how to get & .764 \\
information out of people. & \\
5. I can work out what people like and use it in my favour. & .757 \\
4. I am good at mind reading. & .684 \\
2. I would be a good poker player because I can tell when & .651 \\
people are bluffing. & \\
$\begin{array}{l}\text { 1. I can read people well enough to be able to manipulate } \\
\text { them if I need to. }\end{array}$ & .590 \\
Eigenvalue & 2.904 \\
Variance (\%) & 47.94 \\
\hline
\end{tabular}

These items were generated for the face validity and to offer a preliminary investigation of this construct with the expectation that should it prove valid, then scale development should follow. Items were generated from a review of the literature on the cognitive dimensions of empathy. A number of items were discussed with the mental health research team and rated for face validity (five members, two of whom were clinicians familiar with how people can use empathy manipulatively). We sought to keep this measure short as a preliminary investigation and each item should have face validity. It has the instruction: "Below are a series of statements concerning your ability to understand what others might feel and think. Please read each sentence and circle the option which applies best to you using the following scale". Participants rate a five point Likert scale from zero ("Not at all like me") to four ("Extremely like me). We deliberately kept these at mild levels of intensity.

\section{Depression, Anxiety and Stress Scale (DASS-21) [35]}

This 21-item scale consists of three subscales measuring depression, anxiety and stress. Participants rate how much each statement applied to them over the past week; zero ("Did not apply to me at all") to four ("Applied to me very much, or most of the time"). The Cronbach's alphas are .94 for depression, .87 for anxiety and .91 for stress [2].

\section{Results}

Data analysis

Data was analysed using SPSS version 19 and checked for normality of distribution and outliers. Five outliers were identified and removed, leaving $N=199$. Skewness values ranged from -.69 to 1.23 and kurtosis values ranged from -.86 to .91 . 


\section{Descriptives}

\section{Factor structure of the new Competitive Empathy}

Scale

Exploratory factor analysis (Maximum Likelihood extraction) on the competitive perspective-taking scale produced one single factor with an eigenvalue above one explaining $47.94 \%$ of the variance. Table 1 shows the factor loadings. The Cronbach's alpha was .82 . The KaiserMeyer-Olkin (.81) and Bartlett's Test of Sphericity ( $p$ $=.000)$ both indicate the sample size is adequate for factor analysis [16].

Means, standard deviations and Cronbach's alphas of all variables are presented in Table 2 along with gender differences from a $t$ test analysis.

\section{Correlation analysis}

Table 3 provides the two-tailed Pearson product moment correlations for the compassion and empathy measures and Table 4 provides correlations on how these measures link to self-evaluative measures (shame and self-criticism), submissive behaviour and depression, anxiety and stress. We wanted to explore the relationships between 'genuine' compassion and submissive compassion and their associations with different forms of empathy. However, we found that compassionate goals and self-image goals were correlated $(r=.31$, $p>$.001). So in order to get a 'purer' form of compassion we controlled for self-image goals when looking at the correlations between compassionate goals and other variables.

\section{Competitive perspective-taking}

Our new measure was significantly correlated with cognitive empathy but not with emotional reactivity or social skills. The correlation with the empathy total approached significance $(r=.14, p=.05)$. This supports the hypothesis, at least minimally, that when people have cognitive empathy they can recognise they could use those skills to manipulate others for self-interest.

\section{Submissive vs genuine compassion}

Submissive compassion had a negative correlation with social skills. The negative correlation with the Reading the Mind in the Eyes test approached significance $(r=-.14, p=.06)$. There were no correlations with other variables. In contrast, compassionate goals (after controlling for self-image goals) were moderately correlated with all three factors of the empathy quotient and the empathy total.

\section{Empathy quotient}

Interestingly, the empathy quotient and its subscales were not correlated with the Reading the Mind in the

Table 2 Means, standard deviations and Cronbach's alphas of study variables; means in males and females and t tests

\begin{tabular}{|c|c|c|c|c|c|c|}
\hline Scale & $\begin{array}{l}\text { Cronbach's } \\
\text { alpha }\end{array}$ & $\begin{array}{l}\text { Mean (SD) } \\
N=199\end{array}$ & $\begin{array}{l}\text { Mean }(S D) \\
\text { Male }(N=88)\end{array}$ & $\begin{array}{l}\text { Mean }(S D) \\
\text { Female }(N=111)\end{array}$ & $t$ & $P$ \\
\hline Competitive Perspective Taking (CPT) & .82 & $7.87(4.69)$ & $8.77(4.86)$ & $7.15(4.45)$ & 2.44 & $.016^{*}$ \\
\hline Reading the Mind in the Eyes Test (RMET) & .72 & $24.69(5.14)$ & $24.47(4.81)$ & $24.86(5.4)$ & -.543 & .588 \\
\hline Empathy Quotient (EQ) Total & .86 & $30.2(9.16)$ & $27.36(9.09)$ & $32.45(8.6)$ & -4.04 & $.000 * *$ \\
\hline EQ Cognitive Empathy & .86 & $14.71(5.35)$ & $13.56(5.74)$ & $15.63(4.86)$ & -2.76 & .006 \\
\hline EQ Emotional Reactivity & .78 & $13.03(4.91)$ & $11.18(4.46)$ & $14.5(4.78)$ & -5 & .000 \\
\hline EQ Social Skills & .56 & $7.39(2.72)$ & $7.07(2.56)$ & $7.65(2.82)$ & -1.5 & .135 \\
\hline Submissive Compassion (Sub. Comp.) & .88 & $19.74(8.56)$ & $19.92(7.82)$ & $19.6(9.13)$ & .25 & .799 \\
\hline Compassionate Goals (Comp. Goals) & .71 & $24.56(4.4)$ & $24.48(4.2)$ & $24.62(4.56)$ & -.23 & .819 \\
\hline Self-Image Goals & .75 & $15.96(4.81)$ & $16.42(4.73)$ & $15.59(4.87)$ & 1.2 & .230 \\
\hline Submissive Behaviour Scale (SBS) & .84 & $19.26(9.25)$ & $22.92(8.11)$ & $25.32(9.97)$ & -1.83 & .070 \\
\hline Other as Shamer Scale (OAS) & .92 & $22.36(11.89)$ & $22.64(12.07)$ & $22.13(11.79)$ & .30 & .764 \\
\hline FSCSRS Inadequate Self & .89 & $17.89(8.55)$ & $17.56(7.9)$ & $18.15(9.05)$ & -.48 & .631 \\
\hline FSCSRS Reassured Self & .83 & $21.11(5.39)$ & $21.57(5.21)$ & $20.75(6.44)$ & .97 & .331 \\
\hline FSCSRS Hated Self & .78 & $3.43(3.75)$ & $4.02(4.01)$ & $2.96(3.49)$ & 1.985 & $.048^{*}$ \\
\hline DASS Depression & .86 & $4.43(4.53)$ & $4.86(4.74)$ & $4.07(4.34)$ & 1.215 & .226 \\
\hline DASS Anxiety & .81 & $5.18(4.48)$ & $5.18(4.61)$ & $5.18(4.39)$ & .009 & .993 \\
\hline DASS Stress & .84 & $7.19(4.9)$ & $6.77(4.86)$ & $7.53(4.92)$ & -1.08 & .284 \\
\hline
\end{tabular}

${ }^{*} p<0.05 ;{ }^{* *} p<0.01$ are significance in bold 
Table 3 Pearson's correlations between empathy measures, submissive compassion, compassionate goals and self-image goals

\begin{tabular}{|c|c|c|c|c|c|c|c|}
\hline & RMET & $\begin{array}{l}\text { (EQ) } \\
\text { Total }\end{array}$ & $\begin{array}{l}\text { (EQ) Cognitive } \\
\text { Empathy }\end{array}$ & $\begin{array}{l}\text { (EQ) Emotional } \\
\text { Reactivity }\end{array}$ & $\begin{array}{l}\text { (EQ) Social } \\
\text { Skills }\end{array}$ & CPT & Sub. Comp. \\
\hline (EQ) Empathy Quotient Total & .09 & & & & & & \\
\hline (EQ) Cognitive Empathy & .07 & $.86^{* *}$ & & & & & \\
\hline (EQ) Emotional Reactivity & .06 & $.85^{* *}$ & $.56^{* *}$ & & & & \\
\hline (EQ) Social Skills & .12 & $.71^{* *}$ & $.52^{* *}$ & $.41^{* *}$ & & & \\
\hline CPT & -.03 & $.14^{\mathrm{a}}$ & $.33^{* *}$ & -.06 & .07 & & \\
\hline Submissive Compassion & $-.14^{\mathrm{a}}$ & .07 & .11 & .13 & $-.17^{*}$ & .07 & \\
\hline Compassionate Goals (controlling for self-image goals) & .13 & $.47^{* *}$ & $.40^{* *}$ & $.49 * *$ & $.23^{* *}$ & .05 & .02 \\
\hline Self-Image Goals & -.02 & $-.16^{*}$ & -.06 & -.13 & $-.28 * *$ & $.20^{* *}$ & $.42^{* *}$ \\
\hline
\end{tabular}

EQ Empathy quotient, CPT Competitive perspective taking scale, RMET Reading the mind in the eyes test, Sub Comp Submissive compassion ${ }^{*} p<0.05 ;{ }^{* *} p<0.01$ are significance in bold

a approaches significance $(p<.06)$

Eyes test. The relationship of this variable with others has been reported above.

\section{Self-evaluative measures}

Table 4 provides the Pearson correlations for empathy and compassion variables with self-evaluation and mood anxiety and stress variables.

\section{Multiple regression}

We conducted a multiple linear regression (Enter method) with submissive compassion, compassionate goals, self-image goals, shame and submissive behaviour as the independent variables and the empathy total as the dependent variable. Analysis of regression plots of standardized residuals against standardized predicted values, histograms and P-P plots showed that assumptions of linearity and normality of distribution were met. There was no evidence of multicollinearity (i.e. tolerance $>.20$ \& VIF $<5.00,[15])$. The analysis accounted for
$32 \%$ of the variance in the prediction of the total Empathy Quotient score $[\mathrm{F}(5,188)=17.63, p<.001]$. Compassionate goals were the strongest predictor $(\beta=.46, p$ $<.001)$, followed by (lower) self-image-goals $(\beta=-.29, p$ $<.001)$, submissive compassion $(\beta=.29, p<.001)$, and external shame $(\beta=-.23, p=.003)$. Submissive behaviour was not a significant predictor of empathy in this model $(\beta=.10, p=.207)$ (see Table 5).

\section{Discussion}

Given that many people working in the health and other helping services are called to behave compassionately, understanding the motives behind compassion and the skills people bring to the caring role is important. One area of interest is therefore peoples attempts to be compassionate not (just) for the benefit necessarily of the other, but for self-focused reasons. Hence, this study had three basic aims: to explore in more detail the phenomena of submissive compassion and its link to empathy and self-evaluative processes; to develop and explore the value of a self-report scale exploring people's capacity to

Table 4 Pearson's correlations between empathy measures, submissive compassion, compassionate goals (controlling for self-image goals) and self-image goals and submissive behaviour, external shame, self-criticism and depression, anxiety and stress

\begin{tabular}{|c|c|c|c|c|c|c|c|c|c|}
\hline & RMET & $\begin{array}{l}\text { (EQ) } \\
\text { Total }\end{array}$ & $\begin{array}{l}\text { (EQ) Cognitive } \\
\text { empathy }\end{array}$ & $\begin{array}{l}(E Q) \text { Emotional } \\
\text { reactivity }\end{array}$ & $\begin{array}{l}\text { (EQ) Social } \\
\text { skills }\end{array}$ & CPT & Sub. comp. & Comp. goals & $\begin{array}{l}\text { Self-image } \\
\text { Goals }\end{array}$ \\
\hline SBS & -.06 & $-.18^{*}$ & -.11 & -.06 & $-.35^{* *}$ & -.04 & $.42^{* *}$ & .03 & $.41^{* *}$ \\
\hline OAS & -.03 & $-.24^{* *}$ & -.12 & $-.17^{*}$ & $-.39^{* *}$ & .02 & $.45^{* *}$ & -.09 & $.33^{* *}$ \\
\hline (FSCSRS) Inadequate self & -.02 & -.08 & .00 & -.00 & $-.21^{* *}$ & .09 & $.48^{* *}$ & -.03 & $.35^{* *}$ \\
\hline (FSCSRS) Hated self & -.06 & $-.27^{* *}$ & $-.15^{*}$ & $-.23^{* *}$ & $-.32^{* *}$ & .07 & $.31^{* *}$ & $-.14^{\mathrm{a}}$ & $.22^{* *}$ \\
\hline (FSCSRS) Reassured self & -.01 & $.14^{*}$ & $.15^{*}$ & .05 & $.24^{* *}$ & .12 & $-.28^{* *}$ & $.17^{*}$ & $-.16^{*}$ \\
\hline (DASS) Depression & -.11 & $-.22^{* *}$ & -.10 & $-.20^{* *}$ & $-.30^{* *}$ & .11 & $.36^{* *}$ & -.05 & $.25^{* *}$ \\
\hline (DASS) Anxiety & $-.18^{*}$ & $-.17^{*}$ & -.07 & -.11 & $-.31^{* *}$ & $.20^{* *}$ & $.41^{* *}$ & -.04 & $.32^{* *}$ \\
\hline (DASS) Stress & -.11 & -.09 & -.02 & -.03 & $-.30^{* *}$ & .11 & $.44^{* *}$ & .03 & $.35^{* *}$ \\
\hline
\end{tabular}

RMET Reading the mind in the eyes test, SBS Submissive behaviour scale, OAS Other as shamer scale, FSCSRS Forms of self-criticising and self-reassuring scale, DASS Depression, anxiety and stress scale, EQ Empathy quotient, CPT Competitive perspective taking scale, Sub Comp Submissive compassion, Comp Goals Compassionate goals ${ }^{*} p<0.05 ;{ }^{* *} p<0.01$ are significance in bold

approaches significance $(p<.06)$ 
Table 5 Multiple linear regression with empathy quotient as dependent variable and submissive compassion, submissive behaviour, compassionate goals, self-image goals and external shame as independent variables

\begin{tabular}{llll}
\hline & $B$ & SE B & $\beta$ \\
\hline Constant & 15.97 & 3.38 & \\
Submissive Compassion & .30 & .08 & $.29^{* *}$ \\
Submissive Behaviour & -.10 & .08 & -.10 \\
Compassionate Goals & .96 & .13 & $.46^{* *}$ \\
Self-image goals & -.56 & .14 & $-.29^{* *}$ \\
External Shame & -.18 & .06 & $-.23^{*}$ \\
\hline$R^{2}=.32$
\end{tabular}

$R^{2}=.32(p<.001) ;{ }^{*} p<.01 ;{ }^{* *} p<.001$

recognise an ability to use their empathy for selfpromoting reasons; and potential gender variations in these social competencies and skills.

In regard to the first question of how submissive compassion relates to empathy, this study suggests they are unrelated or minimally so. While there is a significant negative correlation with 'reading the mind in the eyes test' and also social skills (Table 3) these correlations are small. The data on self-image goals (which correlate significantly with submissive compassion) also reveals a small negative correlation with the social skills aspect of empathy. What is most striking, however, is that the defensive motives captured by the concept of submissive compassion and also self-image goals are both significantly linked to submissive behaviour in general, shame, negative self-evaluation, lower self-reassurance and symptoms of depression, anxiety and stress. Although we cannot test it here, it is possible that it is the sense of social fragility and negative self-evaluation that partly drives the need to be submissively compassionate.

In regard to our second question, of whether people can recognise their ability to use empathy for selffocused reasons the answer would support 'yes they can'. For example, people who scored higher on cognitive empathy also scored higher on competitive self-focused empathy. Or to put this another way, the more cognitive empathy you have, the more you recognise you can use it for self-benefit. Table 3 also reveals that empathy is correlated with compassion goals (after controlling for self-image goals).

What is also interesting is that compassion motivation is not related to the degree to which an individual sees themselves as being able to use empathy for self-focused or manipulative purposes. However, interestingly selfimage goals are marginally but significantly correlated with self-focused empathy. Perhaps this is because people are more motivated to try to generate positive images of themselves in the minds of others and are more attuned to those motives within themselves.
Looking at the relationships between empathy variables and self-evaluation, depression, anxiety and stress, the relationship was mostly negative. Although these correlations are relatively small it does suggest that empathic difficulties, especially with social skills are related to increase tendencies for negative self-criticism, depression, anxiety and stress. It would make sense then that compassion focused therapy would need to focus on developing empathic competencies [20, 29].

We were also interested in the gender variations in these motives and competencies. nn provides the basic standard deviations and gender differences. In line with other studies [13, 31], women scored higher on both cognitive and emotional reactivity but not on social skills aspects of empathy. Second, women scored significantly lower on our new measure of recognising one's ability to use empathic competencies and skills for self-focused and beneficial reasons. Interestingly, they did not differ on hardly any of the other motivational variables such as compassionate goals, self-image goals or submissive compassion. Nor did the genders differ on variables such as shame and negative self-evaluation, although men scored slightly higher on hated self.

Looking at the predictors for empathy our multiple regression revealed that compassionate goals were highly associated with empathy, whereas shame and self-image goals appear to be inhibitors. When these variables are controlled, submissive compassion becomes positively associated with empathy. This may indicate that it's the shame and defensive self-focusing within submissive compassion that interferes with empathy rather than them being low on caring motivation itself. So the study suggests that compassion and empathy are affected by underlying motives and the degree to which one is threatened, shame-prone and critically self-focused.

\section{Conclusion}

This study suggests the importance of separating out a motivation for caring from its competencies of empathy and in particular the perspective-taking aspect of empathy. For example, there is no correlation at all between people's ability to be aware they can use empathy for self-interest and caring goals. So while compassion as a motivational system draws on different competencies to pursue its goal; these competencies can be used in different ways by the same person. Data of this kind suggests that when clinical trainers focus on empathytraining they also need to focus on motivation training and in particular the nature of genuine compassion motivation $[20,29]$.

\section{Limitations}

This is a cross-sectional study with a student population that comes with limitations regarding the difficulties of 
making casual inferences and stability of findings. We also raise a caution in studies like ours because if we're trying to separate motivation from competency it's important that scales do not combine motives (desire to be caring) with competencies such as (being able to emotionally connect to people's feelings or perspective take). The Empathy Quotient might do that at times. For example, items like "I really enjoy caring for other people" is about caring interest, not necessarily empathy. They might enjoy caring but not be very empathic or good at it. We are aware that our new scale may be slightly unintentionally gender biased in the sense that the scale asks questions like could you be a good interrogator or poker player. However, our idea is to raise this as an area for research that others may contribute to and devise better measures of how we can use empathy in different ways with different motives. Nonetheless, this study may add to the literature on teasing apart what is linked to genuine compassionate motives and what is linked to competencies that can be used to advance social motives of which compassion may be one.

\section{Abbreviation}

VIF: Variance inflation factor

\section{Acknowledgements}

We are grateful to all the students who completed the questionnaires.

\section{Funding}

The authors declare that they have no funding for the research reported.

\section{Availability of data and materials}

The materials described in the manuscript are readily reproducible, including database and all relevant data. Databases as described in the manuscript are available upon request from the researchers in a way that preserves anonymity.

\section{Authors' contributions}

All authors have made substantial contributions to this study; PG was responsible for the study design. FC, JS, LC and RM collected the data. PG and $F C$ was responsible for the initial data analysis and the writing of manuscript. All authors took part in the interpretation of data and drafting of the manuscript. All authors critically revised, read and approved the final manuscript.

\section{Competing interests}

The authors declare that they have no competing interests.

\section{Consent for publication}

Written informed consent and consent for publication was provided by the participants of the study.

\section{Ethics approval and consent to participate}

Ethical approval was obtained from the University of Derby Psychology Research Ethics Committee, Ethics Ref No: 079-13-PG.

\section{Publisher's Note}

Springer Nature remains neutral with regard to jurisdictional claims in published maps and institutional affiliations.

\section{Author details}

${ }^{1}$ College of Health and Social Care Research Centre, Centre for Compassion Research and Training, University of Derby, Derby, UKDE22 1GB. ${ }^{2}$ Clinical Psychology Unit, Western Bank, University of Sheffield, Sheffield S10 2TN, UK. ${ }^{3}$ Faculty of Psychology and Education Sciences, University of Coimbra, Rua do Colégio Novo 3000-115, Coimbra, Portugal. ${ }^{4}$ University of Derby, Kedleston Road, Derby DE22 1GB, UK.

Received: 22 December 2016 Accepted: 27 April 2017

Published online: 25 May 2017

\section{References}

1. Allan S, Gilbert P. Submissive behaviour and psychopathology. Br I Clin Psychol. 1997:36:467-88.

2. Antony MM, Bieling PJ, Cox BJ, Enns MW, Swinson RP. Psychometric properties of the 42-item and 21-item versions of the Depression Anxiety Stress Scales (DASS) in clinical groups and a community sample. Psychol Assess. 1998:10:176-81.

3. Baron-Cohen S, Jolliffe T, Mortimore C, Robertson M. Another advanced test of theory of mind: evidence from very high functioning adults with autism or Asperger syndrome. J Child Psychol Psychiatry. 1997;38:813-22.

4. Baron-Cohen $\mathrm{S}$, Wheelwright $\mathrm{S}$. The empathy quotient: an investigation of adults with Asperger syndrome or high functioning autism and normal sex differences. J Autism Dev Disord. 2004;34:163-75.

5. Baron-Cohen S, Wheelwright S, Hill J, Raste Y, Plumb I. The "Reading the Mind in the Eyes" Test Revised Version: A study with normal adults, and adults with Asperger Syndrome or high-functioning autism. J Child Psychiatry and Psychiatry. 2001;42:241-52.

6. Bègue L, Beauvois JL, Courbet D, Oberlé D, Lepage J, Duke AA. Personality predicts obedience in a Milgram paradigm. J Pers Adv online publ. 2014. doi:10.1111/jopy.12104.

7. Bloom, P. (2016). Empathy and its discontents. Trends in cognitive sciences doi.org/10.1016/j.tics.2016.11.004

8. Bockler A, Tusche A, Singer T. The structure of human Prosociality: Differentiating altruistically motivated, norm motivated, strategically motivated, and self-reported prosocial behaviour. Soc Psychol Pers Sci (advanced on line). 2016. doi:10.1177/1948550616639650.

9. Catarino F, Gilbert P, McEwan K, Baião R. Compassion motivations: Distinguishing submissive compassion from genuine compassion and its association with shame, submissive behaviour, depression, anxiety and stress. J Soc Clin Psychol. 2014;33:399-412.

10. Crocker J, Canevello A. Creating and undermining social support in communal relationships: The role of compassionate and self-image goals. J Pers Soc Psychol. 2008;95:555-75. doi:10.1037/0022-3514.95.3.555.

11. Crocker J, Canevello A. Consequences of self-image and compassionate goals. In: Devine PG, Plant A, editors. Advances in Experimental Social Psychology. New York: Elsevier; 2012. p. 229-77.

12. Decety K, Cowell JM. Friends or foes: Is empathy necessary for moral behavior? Perspect Psychol Sci. 2014;9:525-937. doi:10.1177/ 1745691614545130.

13. Dimitrijević A, Hanak N, Vukosavljević-Gvozden T, Opačić G. Psychometric properties of the Serbian version of the Empathy Quotient (S-EQ) Psihologija. 2012;45(3):257-76.

14. Eisenberg N. Altruistic emotion, cognition and behavior. Hillsdale: N.J. Erlbaum; 1986.

15. Field A. Discovering statistics using SPSS (2nd Ed). London: Sage Publications Ltd.; 2005

16. Field A. Discovering statistics using SPSS. Sage publications. 2009

17. Fredrickson BL, Cohn MA, Coffey KA, Pek J, Finkel SA. Open hearts build lives: positive emotions, induced through loving-kindness meditation, build consequential personal resources. J Pers Soc Psychol. 2008;95:1045-62.

18. Galinsky AD, Maddux WW, Gilin D, White JB. Why it pays to get inside the head of your opponent: The differential effects of perspective taking and empathy in negotiations. Psychol Sci. 2008;19:379-84.

19. Germer CK, Siegel RD. Wisdom and compassion in psychotherapy. New York, NY: Guilford; 2012.

20. Gilbert P. Compassion Focused Therapy: The CBT distinctive features series. London: Routledge; 2010.

21. Gilbert P. The origins and nature of compassion focused therapy. Br J Clin Psychol. 2014;53:6-41. doi:10.1111/bjc.12043.

22. Gilbert P. The evolution and social dynamics of compassion Journal of Social \& Personality Psychology Compass. 2015;9:239-254. doi:10.1111/spc3. 12176.

23. Gilbert P. Compassion as a social mentality: An evolutionary approach. In: P. Gilbert (ed). Compassion: Concepts, Research and Applications. London: Routledge. 2017. p. 31-68. 
24. Gilbert P, Clarke M, Hempel S, Miles JNV, Irons C. Criticizing and reassuring oneself: An exploration of forms style and reasons in female students. $\mathrm{Br} J$ Clin Psychol. 2004;43:31-50.

25. Gilin D, Maddux W, Carpenter J, Galinsky AD. When to use your head and when to use your heart: The differential value of perspective-taking versus empathy in competitive interactions. Personal Soc Psychol Bull. 2013;39:3-16.

26. Goffman E. The presentation of self in everyday life. London: Penguin; 1959.

27. Goss K, Gilbert P, Allan S. An exploration of shame measures: I: The 'other as shamer' scale. Personal Individ Differ. 1994;17:713-7.

28. Hoffmann SG, Grossman P, Hinton DE. Loving-kindness and compassion meditation: Potential for psychological intervention. Clin Psychol Rev. 2011; 13:1126-32.

29. Kirby J, Gillbert P. The emergence of the Compassion Focused Therapies. In: Gilbert P, editor. Compassion: Concepts, Research and Applications. London: Routledge; 2017. p. 258-85.

30. Koren-Karie N, Oppenheim D, Dolev S, Sher S, Etzion-Carasso A. Mothers' insightfulness regarding their infants' internal experience: Relations with maternal sensitivity and infant attachment. Dev Psychol. 2002;38:534-42.

31. Lawrence EJ, Shaw P, Baker D, Baron-Cohen S, David AS. Measuring empathy: reliability and validity of the empathy quotient. Psychol Med. 2004;34:911-24.

32. Leary MR. Self-Presentation: Impression management and interpersonal behavior. Madison Wisconsin: Brown \& Bencmark; 1995

33. Liotti G, Gilbert P. Mentalizing, motivation and social mentalities: Theoretical considerations and implications for psychotherapy. Psychol Psychother Theory Res Pract. 2011:84:9-25.

34. Loewenstein G, Small DA. The scarecrow and the tin man: The vicissitudes of human sympathy and caring. Rev Gen Psychol. 2007;11:112-26. doi:10. 1037/1089-2680.11.2.112

35. Lovibond PF, Lovibond SH. The structure of negative emotional states: Comparison of the Depression Anxiety Stress Scales (DASS) with the Beck Depression and Anxiety Inventories. Behav Res Ther. 1995;33:335-43.

36. Martin Y, Gilbert P, McEwan K, Irons C. The relation of entrapment, shame and guilt to depression in carers of people with dementia. Aging Ment Health. 2006:10:101-6. doi:10.1080/13607860500311953.

37. Meffert H, Gazzola V, den Boer JA, Bartels AAJ, Keysers C. Reduced spontaneous but relatively normal deliberate vicarious representations in psychopathy. Brain. 2013;136:2550-62.

38. Muncer SJ, Ling J. Psychometric analysis of the empathy quotient (EQ) scale. Personal Individ Differ. 2006:40:1111-9.

39. Panksepp J, Panksepp JB. Toward a cross-species understanding of empathy. Trends Neurosci. 2013;36:489-96.

40. Scott JC. Domination and the arts of resistance. New Haven: Yale University Press; 1990.

41. Shirtcliff EA, Vitacco MJ, Graf AR, Gostisha AJ, Merz JL, Zahn-Waxler C. Neurobiology of empathy and callousness: implications for the development of antisocial behavior. Behav sci law. 2009;27(2):137-71.

42. Singer T, Bolz M, editors. Compassion: Bridging practice and science. Leipzig: Max Planck Institute for Human Cognitive and Brain Sciences; 2013.

43. Wakabayashi A, Baron-Cohen S, Wheelwright S, Goldenfeld N, Delaney J, Fine D, Weil L. Development of short forms of the Empathy Quotient (EQShort) and the Systemizing Quotient (SQ-Short). Personal Individ Differ. 2006:41(5):929-40.

44. Weisman O, Aderka IM, Marom S, Hermesh H, Gilboa-Schechtman E. Social rank and affiliation in social anxiety disorder. Behav Ther Res. 2011:49:399-405.

45. Weng HY, Fox AS, Shackman AJ, Stodola DE, Caldwell JZK, Olson MC, Davidson RJ. Compassion training alters altruism and neural responses to suffering. Psychol Sci. 2013:24:1171-80. doi:10.1177/0956797612469537.

46. Zaki J. Empathy: A motivated account. Psychol Bull. 2014;140:1608-47. http://dx.doi.org/10.1037/a0037679.

\section{Submit your next manuscript to BioMed Central and we will help you at every step:}

- We accept pre-submission inquiries

- Our selector tool helps you to find the most relevant journal

- We provide round the clock customer support

- Convenient online submission

- Thorough peer review

- Inclusion in PubMed and all major indexing services

- Maximum visibility for your research

Submit your manuscript at www.biomedcentral.com/submit
Biomed Central 